для украинской и американской молодежи. Наиболее частотные концепты образуют ядро концептосфер, вербализаторами этих концептов выступают слова-реакции с частотностью шесть и выше. Приядерную зону концептосфер формируют концепты, вербализованные реакциями с частотностью 5-2. Единичные реакции представляют концепты, которые формируют периферию концептосфер.

Ядро концептосферы украиноязычной молодежи образуют 10 концептов (СІМ'Я, КОХАННЯ, ЩАСТЯ, ДРУЗІ, ЗДОРОВ'Я, РОЗВИТОК, ДРУЖБА, ПОДОРОЖ, ДІТИ, УСПІХ), ядро концептосферы американской молодежи - 12 концептов (LOVE, FAMILY, FREEDOM, FRIENDS, TRUST, HEALTH, LIFE, MONEY, HAPPINESS, FAITH, PEACE, LOYALTY). Эксперимент показал, что ключевые концепты двух концептосфер не являются уникальными, то есть они практически не отличаются в двух частях эксперимента. Однако наблюдаем определенные различия в мере важности концептов. Анализ приядерной зоны и периферии концептосфер украинской и американской молодежи подтвердил, что набор концептов, которые актуальны для двух лингвокультур, мало отличается, однако ряд концептов, которые образуют приядерную зону концептосферы украинской молодежи, попадают на периферию концептосферы американцев и, наоборот: концепты, относящейся к приядерной зоне концептосферы американской молодежи, по данным эксперимента, образуют периферию концептосферы украинцев. Таким образом, несмотря на единичные, уникальные ассоциации, полученные от представителей двух лингвокультур, эксперимент показал, что составляющими концептосфер украинской и американской молодежи является преимущественно те, которые имеют эквиваленты в обеих лингвокультурах. эксперимент.

Ключевые слова: концепт, концептосфера, ядро, приядерная зона, периферия, ассоциативный

Bondar Tetiana, Rudaia Tetiana. Conceptospheres of the Ukrainian and American Youth. The article deals with the key concepts of cognitive linguistics («concept» and «conceptosphere») and the main methods of their study, in particular the procedure for conducting a free associative experiment. Associative experiments make it possible to obtain spontaneous and impartial reactions reflecting the way of respondents' thinking and their perception of the surrounding reality. Such experiments help to single out concepts that form the conceptosphere of an individual, a certain group of people or nations.

To describe the conceptospheres of the Ukrainian and American youth, a free associative experiment was conducted which involves 60 respondents (30 Ukrainians and 30 Americans) aged 18-25. The experiment was anonymous, so gender differences / similarities were not considered. As a result of the experiment, 591 associations were obtained (Ukrainian respondents gave 291 reactions, Americans - 300). Those reactions are verbalizers of concepts that are relevant to the Ukrainian and American youth. The most frequent concepts form the nucleus of the conceptospheres, the verbalizers of these concepts being reactions with a frequency of 6 and higher. The near-nuclear zone of the conceptospheres is formed by concepts, verbalized by reactions with a frequency of 5-2. Single reactions represent concepts that form the periphery of conceptospheres.

The nucleus of the conceptosphere of the Ukrainian youth is formed by 10 concepts (СIM'Я, КОХАННЯ, ЩАСТЯ, ДРУЗІ, ЗДОРОВ'Я, РОЗВИТОК, ДРУЖБА, ПОДОРОЖ, ДІТИ, УСПІХ), the nucleus of the conceptosphere of the American youth contains 12 concepts (LOVE, FAMILY, FREEDOM, FRIENDS, TRUST, HEALTH, LIFE, MONEY, HAPPINESS, FAITH, PEACE, LOYALTY). The experiment showed that the key concepts of the two conceptospheres are not unique, that is, they practically do not differ in the two parts of the experiment. However, we observe certain differences in the degree of importance of the concepts. Analysis of the near-nuclear zones and peripheries of the conceptospheres of the Ukrainian and American youth confirmed that the set of concepts that are relevant for the two linguocultures does not differ much. However, some of the concepts that form the nucleus of the Ukrainian youth's conceptosphere appear on the periphery of the Americans' conceptosphere, and vice versa: according to the experiments, concepts related to near-nuclear zone of the conceptosphere of the American youth form the periphery of the conceptosphere of the Ukrainians. Thus, despite the single, unique associations received from representatives of the two linguocultures, the experiment showed that the components of the conceptospheres of the Ukrainian and American youth are mainly concepts that have correspondences in both linguocultures.

Key words: concept, conceptosphere, nucleus, near-nucleus zone, periphery, associative experiment.

DOI: https://doi.org/10.32782/2410-0927-2020-13-6

УДК $811.112 .2 ’ 25-115$

Олена Бондарчук, Наталія Лисецька

\title{
КОНЦЕПТУАЛЬНИЙ ПЕРЕКЛАД: ДО ПИТАННЯ ТРАНСФЕРУ КУЛЬТУРНО МАРКОВАНИХ ТЕКСТОВИХ ЕЛЕМЕНТІВ (НІМЕЦЬКА ТА УКРАЇНСЬКА МОВИ)
}

У статті проаналізовано культурно марковану лексику як одну з основних труднощів у перекладі. Зосереджено увагу на транслятології як окремій галузі сучасних перекладознавчих досліджень, визначено переклад як об'ємне поняття у тріаді «мова, текст, культура», описано транслятологію як дисципліну з погляду відмінностей лінгвістичного та концептуального перекладу. У науковій розвідці зосереджено увагу на концептуальному перекладі

(C) Бондарчук О., Лисецьька Н., 2020 
як способі передачі культури. Скопос постає основним важелем для визначення прийомів перекладу безеквівалентної лексики. Важливо передати не прочитане чи почуте, а сказане й подумане, враховуючи функцію, комунікативну мету вихідного тексту. Лінгвістичний переклад для виконання цього завдання $\epsilon$ недостатнім, тому потрібно послугуватися перекладом концептуальним. Проблематика культурно маркованої лексики полягає у відмінностях мови-джерела та мови перекладу. Сюди належать як експліцитні, так і імпліцитні й інтертекстуальні культурні відношення в текстах. Особливу увагу приділено концепту як основному терміну лінгвокультурології та концептології. Наявність концепту у свідомості певної лінгвокультури свідчить про його культурологічну вагомість й актуальність для носіїв мови. Зіставляючи дві культури, виявляємо повні чи часткові лакуни та так установлюється специфіка певної мовної спільноти. Для розуміння й перекладу культурно маркованої лексики недостатньо просто знати лексику та граматику - потрібно мати певні компетенції в міжкультурній комунікації, володіти знаннями про традиції, звичаї, звички, типову поведінку носіїв мови. Коротко описано проблему неологізмів для трансляторів. Запропоновано кроки для дидактизації перекладу культурно маркованої лексики на теоретичних курсах і практичних заняттях із перекладу. Це опис, реконструкція, інтерпретація, визначення культурної значущості. Наведено кілька основних способів для передачі культурно маркованої лексики. У статті підкреслено вагомість перекладача як посередника між двома культурами та важливість рівня його професійності для адекватного та доцільного перекладу.

Ключові слова: культурно маркована лексика, реалії, неологізми, лакуни, концепти, культура, скопос, транслятологія, концептуальний переклад.

Вступ. Останніми роками спостерігаємо посилений інтерес філологів і лінгвістів до проблем перекладу з погляду міжкультурної комунікації. Це закономірно, оскільки він $є$ «умовою, наслідком та процесом міжкультурних контактів: обміну знаннями, ідеями, емоціями, духовними цінностями» [4, с. 7]. Відомий факт, що в мові відображено код нації, культура народу. Тісний нерозривний зв'язок мови й культури неодноразово підкреслював В. фон Гумбольдт, пояснюючи це тим, що природа мови є творчою, вона форма вираження національного духу. Вона не лише інструмент, а й сама діяльність духа. Він стверджує, що в мові закладене сприйняття навколишнього світу й стереотипи поведінки їі носіїв, і вже сам факт, що в мові наявні суто лінгвістичні маркери, які відображають культуру, яскраво свідчать про наявність у кожного народу свого особливого духовного світу [3]. Численний інтерес науковців до проблем зв'язку мови та культури (про це свідчать праці в Україні й за кордоном із таких дисциплін, як концептологія, когнітивна транслятологія, лінгвокультурологія, перекладознавство, прагматика, лінгвостилістика, літературознавство тощо) усе ж не охоплює всі аспекти їх взаємодії. Із відкриттям кордонів, посиленою глобалізацією зростає міграція, збільшується не лише співпраця зі сфери політики, економіки, підприємництва, але й стають багатшими особистісні контакти. Помітними стають труднощі розуміння носіїв іншої культури, комунікативні невдачі, очевидні культурні відмінності, поведінкові риси, різноманітні прояви менталітету.

Запропонована стаття має за мету охопити дослідження культурно маркованої лексики як українських, так і німецьких науковців, а також звернути увагу на такі лексичні одиниці 3 погляду не лише лінгвістичного, а й концептуального перекладу. Поставлена мета передбачає виконання таких завдань: пояснити особливості концептуального перекладу, описати безеквівалентну лексику щодо перекладу та культури, окреслити місце концепту під час концептуального перекладу, визначити способи передачі культурно маркованої лексики.

Результати та дискусії. Лінгвістичний переклад має за основу принцип відтворення тексту зі збереженням формальної структури оригіналу. Іншими словами, це точний, дослівний переклад. Це певною мірою мікропереклад, інструментарій якого не дає змоги відтворити всю семантичну структуру слів (денотативну, конотативну, крім того ще й контекстуальну та авторську в літературних творах). А. М. Науменко наголошує на необхідності іншого підходу до перекладу - концептуального або макроперекладу, - який має за мету передати не слово, а думку, смисл, авторську концепцію, прагматику, творчий задум, культурні особливості. У дослідженнях його ще називають філософським, національно забарвленим, еквівалентним, функціональним, динамічним [8, с. 70]. У цьому контексті потрібно звернути увагу на поняття «неможливості перекладу», коли основними труднощами $є$ «неперекладні слова, віршові форми, стилістичні засоби, а також неперекладні життєві погляди» [5, с. 74]. Відзначимо термінологічне розмаїття досліджуваної теми як в українських, так і в німецьких розвідках: лексика $з$ культурним чи національним компонентом, безеквівалентна лексика, специфічно національна 
лексика, реалія, слово-реалія, лакуна, фонова лексика, екзотизм, історизм, етнографізм, культурема, німецькі відповідники: Kulturspezifikum, Begriffslücke, Fehlstelle, Realia, Nulläquivalenz, kulturelle Elemente, kulturspezifische Elemente, Realienabbild, Realienlexem, kulturspezifischer Ausdruck. У науковій літературі знаходимо праці, спрямовані на відтворення певних одиниць шляхом перекладу Р. Зорівчак, А. Гудманян, І. Ковальова, П. Содомора, Т. Качановська, А. Савенко, А. Пермінова, О. Сизова, М. Бережна, О. Кучма, М. Нечипоренко, Ю. Чала й ін. Лексику з культурними елементами в перекладознавстві вивчали О. В. Федоров, Я. Й. Рецкер, С. П. Флорін, А. Д. Швейцер та ін.

Спробуємо з'ясувати, яким чином виникає безеквівалентна лексика і яке місце займає концептуальний переклад у тріаді «мова, текст, культура». Переклад як мовна діяльність зумовлений складними та багатогранними відношеннями між окремими культурами і $\epsilon$ симбіозом трьох категорій мова, текст, культура в конкретних ситуаціях: «переклад розуміємо як об'ємне поняття, яке утворюється за допомогою перекладу на іншу культуру та трансферу між культурами» [2]. 3 огляду на культурообумовленість текстів культурна когерентність стає важливим фактором для оцінювання якості перекладу, для його адекватності й доцільності. Адекватність потрібно трактувати з погляду на перекладні зв'язки з текстом-оригіналом, а також зв'язки з культурно-культурними особливостями реципієнтів. Переклад як дисципліна набуває нового кола досліджень. У німецькому мовознавстві для позначення перекладу використовують термін Translation - mрансляція, який $є$ ширшим за своїм визначенням за Übersetzen (письмовий переклад) та Dolmetschen (переклад усний). К. Норд визначає трансляцію як «створення цільового тексту, який залежно від поставленої чи очікуваної функції цільового тексту (скопосу трансляту) має різні специфічні зв'язки з наявним текстом-оригіналом. За допомогою трансляції уможливлюється комунікативна дія, яка б не відбулася без неї на тлі наявних мовних та культурних бар'єрів» [9].

Концептуальний переклад як дисципліна сформувався у 20-му столітті, проте його ідеї піднімалися Цицероном (максима перекладати не слово, а думку) і Мартіном Лютером, який вважав, що певні пасажі Біблії неможливо перекласти дослівно, а потрібно передавати їхній смисл. У 60-х роках ця думка була розвинута в поняття динамічної еквівалентності С. Нідою, який вважає, що культурні аспекти тексту треба передавати таким чином, щоб вони були зрозумілі реципієнтам без знань про вихідну культуру $[9 ; 11]$.

У галузі функціональної транслятології термін скопос (ціль, мета, намір) відіграє центральну роль. Теорію скопосу у 80-ті роки започатковано представниками німецької школи Райсом i Вермером (Reiß und Vermeer), основний принцип якої полягає в передачі комунікативної мети тексту, а не в пошуку простого еквівалентного відповідника в цільовій мові [11, c. 177-189].

Переклад культури є непростим завданням, що вимагає ставити фокус не на сказаному, а на задуманому, щоб знайти правильний еквівалент. Розпізнавання задуманого відбувається серед реципієнтів одного кола автоматично, оскільки вони користуються спільними знаннями, досвідом і пам'яттю. Культура передається за допомогою мови, відтак є її складовою частиною. Мова - це відображення культури, а переклад не просто передача інформації з однієї мови іншою, це - трансфер культури. Перекладач виконує роль зв'язного елемента між двома культурами, є соціокультурним посередником і рушійною силою, як удало підкреслює M. I. Іваницька [4]. Кожна спроба перекладу є водночас спробою подолати відмінності між мовою оригіналу та цільовою мовою. Для визначення критичних місць перекладач повинен володіти вмінням визначати відмінності й спільні риси між двома культурами.

Проблематика культурно маркованої лексики в текстах обмежується здебільшого реаліями або культурно-історичними подіями, особами, регіональними варіантами мови, а наукова дискусія щодо культурних елементів зосереджується на вивченні літературних і поетичних текстів. Культурно марковані терміни виникають лише в контексті конкретної мови та становлять велику проблему для перекладача як носія іншої культури. Це, передусім, власні імена, назви професій, географічні терміни, історизми, релігійні поняття тощо. Це реалії, які, за визначенням Е. Маркштайн (Markstein), є «носіями ідентичності національного/етнічного 
утворення, національної/етнічної культури в широкому значенні й приписувані країні, регіону, частині землі» [7, с. 288]. Сюди належать явища, які придумані чи створені людьми, не лише об'єкти культури, а й скорочення, звання, свята, вигуки, звертання, форми прощання. Проте Е. Маркштайн не відносить до цієї групи явища природи (як позначення снігу в різних регіонах) i приказки й ідіоматичні звороти [7]. До критичних лексем належать, на думку Г. Вотьяка, «звертання, форми привітання, власні назви, інституції, географічно-кліматичні феномени, лексеми 3 галузі гастрономії, релігії, суспільні та політичні явища» [13, с. 158f]. Проте не всі культурно марковані одиниці є виражені лексично, іноді їх потрібно вміти відчути між рядками.

Культурні відношення в текстах поділяють на експліцитні й імпліцитні. Експліцитні культурні референції виявляються лексемами та власними назвами з культурномаркованими змістом і формою. На рівні речення й тексту теж можуть виникати експліцитно словосполучення та висловлювання 3 культурно маркованими змістом i формою. Імпліцитні культурні відношення реконструюються з відношень на синтаксичному рівні між реченнями та текстами, де відсутнє експліцитне маркування за допомогою лексеми, яка містить культурне значення. Такі мовні висловлювання передбачають наявність фонових знань реципієнта й семантично не несуть культурного навантаження. Культурна специфіка виявляється лише у створенні паралелей і проєкцій на культурні рамки, на структуровану систему знаків [2].

Тісно пов'язаний із проблематикою експліцитних та імпліцитних культурних маркерів у текстах феномен інтертекстуальних зв'язків. Культурність й інтертекстуальність тісно співвідносяться в текстах і $\epsilon$ рівнозначно релевантними для свідомо оптимізованого перекладацького процесу. Ці додаткові значення стають ключовими, коли вони $є$ основною змістовою складовою частиною в повідомленні, яке потрібно перекласти. Тоді вони стають проблемою перекладу. Традиційними перекладацькими «відлуннями» попередніх текстів можуть бути цитати, монтажі, натяки, плагіат, згадування сталих зразків. Це як окремі слова, синтагми, імпліцитні натяки, так і невербальні знаки як інтертекстуальні натяки.

До культурно маркованої лексики відносимо також неологізми, які найчастіше трапляються в німецькій пресі та стосуються сфери політики. Такі новоутворення відображають певний досвід, ставлення до особи чи явища, колективне бачення проблем, як-от: вирішення питання $з$ прав біженців, їхнього майбутнього в Німеччині. I для перекладача вони становлять чималі виклики. Розглянемо два неологізма політичного дискурсу der Masterplan Migration та Ankerzentren. Аби їх перекласти, треба володіти інформацією про актульний стан проблеми, розуміти контекст, у якому вживаються лексеми. Неологізм Ankerzentren є одним із каменів спотикання для перекладача (Tagesschau, 01.08.2018). 3 одного боку, der Anker актуалізує значення: прибути, кинути якір і залишитися, проте насправді Anker у пібліцистичному дискурсі тлумачиться як скорочення: "Zentrum für Ankunft, Entscheidung, Rückführung" - «Центри прибуття біженців, рішень щодо їх подальшого перебування і їx повернення (AnkER-Zentren)» [6, с. 165], - що також видно і в правописі - літери E та R великі, є скороченнями таких слів: Ank-Ankunft, E-Entscheidung, R-Rückführung.

У сфері лінгвокультурології, концептології та когнітивної лінгвістики вчені говорять про відображення культури, особливостей певної нації в концептах (Н. Д. Арутюнова, С. Г. Воркачов, О. О. Кубрякова, В.В. Красних, Ю.С. Степанов, А. М. Приходько, О. О. Селіванова, С. А. Жаботинська та ін.

Концепт - це «дискретна змістова одиниця колективної свідомості, яка відбиває предмет реального чи ідеального світу й зберігається в національній пам'яті у вербально визначеному вигляді. Концепт становить основне осердя культури в ментальному світі людини, основний елемент культури певного етносу. Концепти є ідеальними, вони кодуються у свідомості одиницями універсального предметного коду, основу яких становлять індивідуальні чуттєві образи, що формуються на базі особистого чуттєвого досвіду людини» [14, с. 34].

Наявність мовного вираження концепту засвідчує його глибинну концептуальну розробку в певному лінгвоетносі, відбиває культурологічну актуальність для його членів. Відсутність вербалізації концепту вказує на незавершеність процесу пізнання предмета або явища навколишньої дійсності в певній культурі. У такому випадку виникає лакуна - наслідок відображення специфічних 
реалій, подій, станів, процесів, феноменів, характерних для певної культури, які можна вважати сигналами певної лінгвокультурної специфіки мовної спільноти [1, с. 55].

Якщо порівнювати німецьку й українську культури, то в українській відсутні такі концепти, вони утворюють лакуни: das Angebot, der Termin, der Eintopf, die Leistung, die Einwegflasche. Тлумачення цих понять можливе крізь призму німецької культури. Відомо, що німці все планують, ведуть щоденник, планують відпустку на рік наперед. Termin - зустріч по роботі, приватна зустріч, прийом у лікаря, запис у певну установу, побачення. Переклад українською мовою залежить від контексту. Einen Termin für die Hochzeit nannte sie jedoch noch nicht. (Die Zeit, 04.07.2012 (online) - Дату весілля вона все ж не назвала (переклад тут і далі наш). Для порівняння наведемо приклад, де Termin уживається в значенні «прийом у лікаря» та «зустріч»: Viele Termine, Verpflichtungen und To-Do's und schon hat man den Termin beim Augenarzt, Zahnarzt oder beim Psychologen vergessen. - Багато зустрічей, обов'язків та справ і ви вже забули про прийом в окуліста, стоматолога чи психолога (blog.ylex.ch, 01.07.2020 (online). Наступний приклад - Einwegflasche - належить до німецького побуту: це пляшка (зі скла або пластику), яка після використання потрапляє до автомата в супермаркеті для переробки. Якщо їі здати, то можна отримати близько 25 центів на касі супермаркету. Для заощадливих німців це добра мотивація. Окрім того, німці є екологічно свідомою нацією; там давно сортують й переробляють сміття, ініціюють багато різних акцій на порятунок природного середовища.

Для української культури характерні концепти кум, літня кухня, вишиванка, хліб, доля, калина, вечорниці, бандура, горілка та ін., які не мають відповідників у німецькій мові й без пояснень, наведення прикладів чи особистого досвіду будуть незрозумілими для носія німецької культури. Наприклад, у заголовку статті вишиванка транслітерована: Vyshyvanka-Boom in der Ukraine. Patriotische Mode im Aufwind, а в підзаголовку вишиванку описано як «національні символи у формі традиційних вишиваних візерунків на сукнях та сорочках»: Seit den MaidanProtesten 2013 erleben nationale Symbole in Form von traditionellen Stickmustern auf Kleidern und Hemden eine Renaissance in der Ukraine (www.deutschlandfunk.de, 03.11.2016 (online).

Для практичних занять із перекладу, розвитку компетенцій майбутніх перекладачів можна використовувати такі кроки, щоб установити культурні зв'язки й могти проаналізувати текст із погляду виявлення індикаторів культури реципієнта: опис, реконструкція, інтерпретація [2]. Опис - змістово-семантичне висловлювання, аналіз аргументативних і змістових структур на поверхні тексту. Реконструкція - аналіз складних передумов та культурних категорій, які активуються за принцип утворень аналогій на другому рівні тексту. Інтерпретація упорядкування всього ситуативно-прагматичного контексту, тлумачення змісту всього тексту, що $\epsilon$ необхідним для реципієнта з огляду на його власний життєвий світ. Формула Лассвела видається нам випробуваною моделлю як для роботи з текстами на занятті DaF, так i для аналізу текстів із перекладознавчої перспективи для виявлення й інтерпретації культурно-специфічних елементів.

Е. Маркштайн вважає, що у виборі певної стратегії для перенесення культурно маркованого виразу основну роль відіграє його культурна значущість у тексті перекладу: «Потрібно спершу зважити, чи ця реалія часто трапляється в тексті-джерелі чи лише один раз, чи важлива вона для опису героїв, для тональності та/чи сюжету вихідного тексту або є другорядною деталлю й може бути передана іншим нейтральним, здебільшого узагальнювальним виразом. Рішення потрібно приймати залежно від конкретного випадку» [7, с. 290]. Якщо зосередитися детальніше на практичній стороні перекладу, то існує декілька способів передати культурно марковану лексику. Можна перейняти іншомовне слово, увести неологізм, лексично його підлаштувати під мову реципієнта (надати йому відповідні закінчення, фонетичні особливості, відмінювати за правилами відповідної мови), можна використати транскрипцію та транслітерацію, подати пояснення у формі покликань чи приміток, додавати коментарі й глосарії, використовувати комбінацію з різних методів. С. Флорін і С. Влахов наводять такі види приблизного перекладу: гіпонімічний переклад, прийом «функціонального аналога» та описовий переклад [1].

Висновки. Концептуальний переклад є процесом складним, багатогранним, який ставить перед перекладачем багато вимог. Відтак К. Райс визначає переклад як «...не науку, а ремесло 
(маючи на увазі перекладачів технічних текстів) та мистецтво (про перекладачів літературних текстів)» [10, с. 9]. Для перекладу культурно маркованої лексики чистих лінгвістичних знань буде недостатньо для адекватної передачі змісту. Завдання перекладача полягає в передбаченні рецепції перекладу в цільовій мові, розуміння того, як читач сприйматиме та розумітиме його, врахуванні фонових знань реципієнта. Удалим він $є$ в тому випадку, коли перекладач добре знає спосіб мислення й норми культури (обох культур) та $\epsilon$ митцем, який спроможний відчути культурні тонкощі й адекватно передати їх, проте питання перекладацьких компетенцій є темою для окремої розвідки.

References
1. Ejger, Henrich. 2014. Aspekty teorii perevoda i izbrannyye poeticheskiye perevody: monografiia. Charkiv: CNU imeni V. N. Karasina.

2. Hennecke, Angelika. 2013. Zum Transfer kulturspezifischer Textbedeutungen. Theoretische und methodische Überlegungen aus einer semiotischen Perspektive. Linguistik Online, 37(1). URL: https://doi.org/10.13092/lo.37.513

3. Humbold, von Wilhelm.1985. Yasyk i filosofiia kultury. Moskwa: Progress.

4. Ivanyztska, Mariia.2015. Osobystist perekladacha $v$ ukrainsko-nimezkyh literaturnyh vzayemynah: monohrafiya. Chernivtsi: Knygy.

5. Koller, Werner. 2001. Einführung in die Übersetzungswissenschaft. Wiebelsheim: Quelle \& Meyer.

6. Lysetska, Nataliia. 2019. “Aktualisatsiya i uzualizatsiya novyh leksem «der Masterplan Migration» ta «Ankerzentren» u nimetskomu politychnomu dyskursi”. Aktualni problem romano-germanskoji filologii ta prykladnoji linhvistyky. Shchernivtsi, № 2(18): 160-167.

7. Markstein, Elisabeth. 1999. Realia. In Snell-Hornby, Mary. Handbuch Translation. Tübingen: Stauffenberg Verlag, 288-291.

8. Naumenko, Anatolii. 2013. Konceptualnyi pereklad: monografiya. Mykolaiv, ChDU im. Petra Mohyly.

9. Nord, Christiane. 2002. Fertigkeit Übersetzen. Ein Kurs zum Übersetzenlehren und -lernen. Berlin: BDÜ Service Verlag (Schriftenreihe des BDÜ 38).

10. Reiss, Katarina. 2000. Grundfragen der Übersetzungswissenschaft. Wiener Vorlesungen von M. Snell- Hornby und M. Kadrić. Wien: WUV-Universitätsverlag.

11. Stolze, Radegundis. 2011. Übersetzungstheorien. Eine Einführung. 6-te überarb. Auflage. Narr, 177-189.

12. Vlahov, Sergei, Florin Sidor. 1980. Neperevodimoe v perevode. M.: Mezhdunarodnije otnosheniia.

13. Wotjak, Gerd. 2011. "Sprache und Kultur - Wie spiegelt sich Kulturelles in der Sprache". Translation - Sprachvariation-Mehrsprachigkeit. Festschrift für Lew Zybatov zum 60. Geburtstag. Frankfurt a. M., 157-178.

14. Zagnitko, Anatoliy. 2017. Linhvokulturologiya: navchalnyi posibnyk dla studentiv vyshchyh navchalnyh zakladiv. Vinnytsia: DonNU imeni Vasyla Stusa.

Бондарчук Елена, Лисецкая Наталия. Концептуальный перевод: к вопросу трансфера культурно спецыфических текстовых элементов (немецкий и украинский языки). В статье анализируется культурно маркированная лексика как одна из основных сложностей при переводе. Внимание сосредотачиваем на транслятологии как отдельной отрасли современного переводоведения; определен перевод как объемное понятие в триаде «язык, текст, культура», описывается транслятология как дисциплина с точки зрения отличий лингвистического и концептуального перевода. В данной научной разведке обращается внимание на концептуальный перевод как способ передачи культуры. Скопос является основным рычагом для определения приемов перевода безэквивалентной лексики. Важно при этом передать не прочитанное или услышанное, а сказаное и подуманое, учитывая функцию, коммуникативную цель исходного текста. Лингвистический перевод для решения этой задачи недостаточен, поэтому следует использовать перевод концептуальный. Проблематика культурно маркированной лексики заключается в различиях языка-источника и языка перевода. Сюда относятся как эксплицитные, так и имплицитные и интертекстуальные культурные отношения в текстах. Особое внимание уделяется концепту как основному понятию лингвокультурологии и концептологии. Наличие концепта в сознании определенной лингвокультуры свидетельствует о его культурологической значимости и актуальности для носителей языка. При сопоставлении двух культур оказываются полные или частичные лакуны и таким образом устанавливается специфика определенной языковой общности. Культурно маркированная лексика, безусловно, относится к лексическому пласту, для понимания которого недостаточно просто знать лексику и грамматику следует иметь определенные компетенции в межкультурной коммуникации, владеть знаниями о традициях, обычаях, привычках, типичном поведении носителей языка. Коротко описывается проблема неологизмов для трансляторов. Предлагаются шаги для дидактизации перевода культурно маркированной лексики на теоретических курсах и практических занятиях по переводу. Это описание, реконструкция, интерпретация, определение культурной значимости. Рассмотриваются несколько основных способов для передачи культурно маркированной лексики. В статье подчеркивается значимость переводчика как посредника между двумя культурами и важность уровня его профессионализма для адекватного и целесообразного перевода.

Ключевые слова: культурно маркированная лексика, реалии, неологизмы, лакуны, концепты, культура, скопос, транслятология, концептуальный перевод. 
Bondarchuk Olena, Lysetska Nataliya. Conceptual Translation: to the Question of Transfer of Culturally Specific Text Elements (German and Ukrainian). The article deals with the culturally branded vocabulary as one of the main folding facilities for the transfer of languages. It focuses on translatology as a separate branch of modern translation studies, defines translation as a three-dimensional concept in the triad "language, text, culture" and describes translatology as a discipline in terms of differences between linguistic and conceptual translation. This exploration focuses on conceptual translation as a means of cultural transmission. Scopos is the main lever for determining the techniques of translating nonequivalent vocabulary. It is important to convey not what is read or heard, but what is said and thought about, given the function, the communicative purpose of the source text. Linguistic translation is not sufficient to solve this task, so conceptual translation should be used. The problem with culturally marked vocabulary is the difference between the source and target languages. This includes both explicit and implicit and intertextual cultural relations in texts. Special attention is paid to the concept as the basic concept of linguistic and cultural studies. The presence of the concept in the consciousness of a certain linguoculture testifies to its cultural significance and relevance for native speakers. At comparison of two cultures there are full or partial lacunas and thus specificity of the certain linguistic community is established. Culturally marked vocabulary certainly refers to the lexical layer, for understanding which it is not enough just to know the vocabulary and grammar, it is necessary to have certain competences in intercultural communication, to know about traditions, customs, habits, typical behavior of native speakers. The problem of neologisms for translators is briefly described. Steps are proposed to didacticate the translation of culturally marked vocabulary in theoretical courses and practical translation exercises. This is a description, reconstruction, interpretation, definition of cultural significance. Several basic ways to translate culturally marked vocabulary are considered. The article emphasizes the importance of a translator as an intermediary between two cultures and the importance of his level of professionalism for adequate and appropriate translation.

Keywords: vocabulary, realities, neologisms, lacunas, concepts, culture, scopos, translatology, conceptual transfer.

DOI: https://doi.org/10.32782/2410-0927-2020-13-7

УДК 81:159.922

Наталія Бурка

\section{ОБГРУНТУВАННЯ МЕЖ ПІДЛТКОВОГО ВІКУ ДЛЯ ЛІНГВО-КОГНІТИВНИХ ДОСЛІДЖЕНЬ}

У статті з погляду лінгво-когнітивних міждисциплінарних наукових пошуків на основі класичних надбань психології запропоновано новий підхід до розв'язання проблеми обгрунтування раціональних меж підліткового віку людини, що має забезпечити адекватне використання результатів лінгвістичних досліджень у суміжних із нею галузях знання. На підставі аналізу суперечливої взаємодії наслідків, що характеризують особливості онтогенезу та філогенезу підлітка як об'єкта лінгво-когнітивного розгляду сформульовано визначення особливостей його психологічного навантаження у взаємодії з макро- та мікросоціальним оточенням. Окреслено одночасну супервентну дію багатьох причин формування загальної поведінки підлітка на результати його комунікативної соціалізації та показано, що чинники, комплекси яких визначають характер саморозвитку його комунікативної практики, мають різну природу й вирізняються інтенсивністю їх дії на специфіку мовленнєвої поведінки. Шляхом системного зіставного аналізу змістового насичення концептуальних основ наукових праць Р. А. Абдурахманова, Б. Г. Ананьєва, Л. І. Божович, Л. Вовканич， С Крася， В.В.Давидової， І.В.Дубровіної， Е. Ериксона， І. С. Кона, В. Ф. Моргуна, Д. П. Сидоренка, М. М. Смирнягіної, Н. Ю. Ткачової й інших щодо питань установлення причин і меж підліткового віку людини, з'ясовано ступінь варіювання цих меж у психології. На цій підставі сформовано графічний образ площини альтернатив визначень меж підліткового віку людини в наукових працях із психології, за допомогою якого встановлено, що, по-перше, у лінгво-когнітивних дослідженнях доцільно визначати підлітковий вік людини межами від 8-ми років до 19 включно з подальшим його диференціюванням на початковий період (8-9-1011 років), середній (12-13-14-15 років) і завершальний (16-17-18-19 років).

Ключові слова: лінгво-когнітивне дослідження, підлітковий вік, межі, періоди.

Вступ. Сучасний стан стрімкого розвитку різноспрямованих лінгво-когнітивних досліджень породжує багато нових питань міждисциплінарного характеру. До них насамперед потрібно віднести назрілу необхідність термінологічної уніфікації описів загальновідомих когнітивних явищ, розробки відповідних вербально-графічних моделей та образів, спроможних відігравати роль ефективних пропедевтично-наочних засобів для ознайомлення дослідників-

(C) Бурка Н., 2020 